\title{
THE EFFECT OF CURCUMIN ON THE PROLIFERATION AND EXTRACELLULAR MATRIX PRODUCTION IN ETHANOL-INDUCED HEPATIC STELLATE CELLS
}

\author{
RAHMANIAH RAHMANIAH ${ }^{1}$, MELVA LOUISA ${ }^{2 *}$, BANTARI W. K. WARDHANI ${ }^{1}$, VIVIAN SOETIKNO ${ }^{2}$ \\ ${ }^{1}$ Department of Biomedical Sciences, Faculty of Medicine, Universitas Indonesia, Jakarta, Indonesia. ${ }^{2}$ Department of Pharmacology and \\ Therapeutics, Faculty of Medicine, Universitas Indonesia, Jakarta, Indonesia. Email: melva.louisa@gmail.com
}

Received: 20 August 2018, Revised and Accepted: 07 February 2019

\section{ABSTRACT}

Objectives: In various liver disease models, including those for alcoholic liver diseases, curcumin, a polyphenolic compound derived from Curcuma longa, is known to have an hepatoprotective effect. However, the mechanism of action underlying its effects on alcohol-induced hepatic fibrosis remains unknown. We aimed to investigate the mechanisms of action underlying the effects of curcumin, mainly involving the transforming growth factor (TGF)- $\beta /$ Smad pathway.

Methods: Hepatic stellate cells (HSCs), LX2, were incubated with $50 \mathrm{mM}$ ethanol with or without curcumin (1 and $10 \mu \mathrm{M})$. Viable HSCs were counted using a LUNA ${ }^{\mathrm{TM}}$ automated cell counter, whereas the expressions of TGF- $\beta$, Smad3, tissue inhibitor of metalloproteinases-1 (TIMP-1), and type 1 collagen mRNA were measured using quantitative reverse transcriptase polymerase chain reactions.

Results: Curcumin significantly suppressed ethanol-induced HSCs proliferation. The antiproliferative effect of curcumin appeared to be dose dependent. In addition, the mRNA expressions of TGF- $\beta$, Smad3, TIMP-1, and type 1 collagen decreased in the cells treated with curcumin.

Conclusion: Curcumin seems to attenuate ethanol-induced HSCs proliferation through the suppression of TGF- $\beta$ and appears to reduce the production of extracellular matrix as shown by the decreased expression of type 1 collagen.

Keywords: Curcumin, Transforming growth factor- $\beta$, Smad, Tissue inhibitor of metalloproteinases-1, Type 1 collagen.

(c) 2019 The Authors. Published by Innovare Academic Sciences Pvt Ltd. This is an open access article under the CC BY license (http://creativecommons. org/licenses/by/4. 0/) DOI: http://dx.doi.org/10.22159/ijap.2019.v11s1.16119

\section{INTRODUCTION}

Heavy alcohol consumption is a causal factor of multiorgan dysfunction, including alcoholic liver disease (ALD) [1]. The clinical manifestations of ALD may vary depending on the disease stage, which can range from steatosis (fatty liver) to alcoholic hepatitis (fatty liver with inflammation). The condition can continue to progress to liver fibrosis, cirrhosis, and hepatocellular carcinoma [2].

Liver fibrosis is an excessive accumulation of extracellular matrix (ECM) as a response to liver injuries. Hepatic stellate cells (HSCs) are known to play an important role in the development of liver fibrosis. HSCs remain inactive in the normal liver as retinoid storage cells and are activated during the processes leading to liver fibrosis. Many in vitro and in vivo studies have confirmed that chronic alcoholism induces HSC activation [3-5]. Activation of HSCs is characterized by increased cell proliferation, enhanced matrix production, and expression of a number of proliferative and profibrogenic cytokines and their receptors [5].

Transforming growth factor (TGF)- $\beta$ is an important profibrogenic cytokine that plays a key role in HSC activation and proliferation. TGF- $\beta$ inhibits ECM degradation by suppressing the matrix metalloproteinases (MMPs) and promoting its natural inhibitor, the tissue inhibitor of metalloproteinases (TIMPs) [6-8]. The most recognized pathway in myofibroblast formation and matrix production is the TGF- $\beta / \mathrm{Smad}$ pathway [7]. TIMP-1 is expressed by HSCs as a response to hepatic inflammation. The majority of these markers are involved in the TGF- $\beta$ / Smad pathway through phosphorylation of Smad 2/3 and affect the transcription level in nucleus [9-11].

Curcumin is the major active substance of the plant Curcuma longa. Curcumin is a polyphenol, and it is well known for its anti-inflammatory activity in hepatocytes. Many studies show that curcumin exerts a hepatoprotective effect in various liver disease models, including ALD [12]. However, the underlying mechanism by which curcumin exerts its protective effects on alcohol-induced hepatic fibrosis remains unknown. In this study, we aimed to investigate the mechanism of action of curcumin on alcohol-induced hepatic fibrosis mainly through TGF- $\beta /$ Smad pathway.

\section{METHODS}

\section{Materials}

Human immortalized HSCs (LX2) were obtained commercially from Merck Millipore (USA). Curcumin was purchased from Plamed, China. Absolute alcohol was purchased from Merck, USA. Dimethyl sulfoxide was purchased from Vivantis (Malaysia). Dulbecco's Modified Eagle's Medium (DMEM)-high glucose, fetal bovine serum (FBS), penicillin/ streptomycin, and amphotericin B (Fungizone ${ }^{\circledR}$ ) were purchased from Biowest (USA). MTS Assay Kit was purchased from Promega (USA). High Pure RNA Isolation Kit, Transcriptor First Strand cDNA Synthesis Kit, and FastStart DNA Master SYBR Green I kit were obtained from Roche (USA).

\section{LX2 culture}

Human HSCs, LX2, were cultured and maintained at $37^{\circ} \mathrm{C}$ in a $5 \% \mathrm{CO}_{2}$ air atmosphere in DMEM-high glucose supplemented with $10 \%$ heatinactivated FBS, $10 \mathrm{U} / \mathrm{L}$ penicillin, $100 \mu \mathrm{g} / \mathrm{mL}$ streptomycin, and $2.5 \mu \mathrm{g} /$ $\mathrm{mL}$ amphotericin B. Curcumin were given to the cells with or without alcohol.

Cells were seeded at 5000 cells per well in a 12 -well plate and incubated for $72 \mathrm{~h}$. Curcumin 1 and $10 \mu \mathrm{M}$ were added to the cells with or without prior treatment with alcohol $50 \mu \mathrm{M}$ for $24 \mathrm{~h}$. The dose of curcumin was selected on the basis of our previous study by Lin et al. [13] in the cultured HSC from rats. After $24 \mathrm{~h}$ of curcumin treatment, 
cells were harvested and counted for cell viability using Trypan Blue Exclusion Method. Harvested cells were isolated for total RNA and further synthesized to cDNA for real-time polymerase chain reaction (PCR) analysis. Experiments were done 3 times in duplicate.

\section{Quantitative reverse transcription PCR analysis}

Total cellular RNA was extracted from 1,000,000 cells following trypsinization, using High Pure RNA Isolation Kit (Roche, USA). Then, $1 \mu \mathrm{g}$ of RNA was converted to cDNA using a Transcriptor First Strand cDNA Synthesis Kit (Roche, USA). A quantitative real-time PCR was performed on $100 \mathrm{ng}$ cDNA using FastStart DNA Master SYBR Green 1 kit (Roche, USA) according to the manufacturer's protocol with $\beta$-actin as housekeeping gene. Primer sequences for TGF- $\beta$-Fwd: 5'-TGAACCGGCCTTTCCTGCTTCTACATG-3'; TGF- $\beta$-Rev: 5'-GCGGAAGTCAATGTACAGCTGCCGC-3'; Smad3-Fwd: GTCTGCAAGAT CCCACCAG, Smad3-Rev: AGCCCTGGTTGACCGACT; collagen 1A1 (Col1A1)-Fwd: AGGTCCCCCTGGAAAGAA, Col1A1-Rev: AATCCTCG AGCACCCTGA; TIMP1-Fwd: GGCTGTGAGGAATGCACA; TIMP1-Rev: TGG AAGCCCTTTTCAGAGC; $\beta$-actin-Fwd: 5'GCTGGAAGGTGGACAGCGA-3'; $\beta$-actin-Rev: 5'-GGCATCGTGATGGACTCCG-3'.

\section{Statistical analysis}

Results were presented as mean \pm standard deviation. Statistical analysis was performed using one-way analysis of variance. Statistical significance was determined at the level of $\mathrm{p}<0.05$.

\section{RESULTS}

Our results showed that alcohol increased the cell viability by approximately two-fold that of the control. Treatment with curcumin appeared to normalize cell viability; however, a higher dose of curcumin leads to a significant decrease of cell viability compared with the control (Fig. 1).

The increased cell viability was in accordance with the increase in TGF- $\beta$ mRNA and Smad3 mRNA expressions. With curcumin treatment, the increases in TGF- $\beta$ mRNA and Smad3 mRNA expressions approached normal values (Figs 2 and 3 ).

Treatment with alcohol resulted in an increase in the expression of Col1A1. Curcumin at a low dose did not reverse the increase in Col1A1 expression; however, a high dose of curcumin increased the expression of Col1A1 even more markedly than alcohol alone (Fig. 4).

The mRNA expression of TIMP increased with alcohol. Curcumin considerably decreased the mRNA expressions of TIMP-1, even to values below the normal (Fig. 5). However, no dose-dependent effect was observed.

\section{DISCUSSION}

It has been demonstrated in previous studies that curcumin had antifibrotic activity in many liver diseases, including ALD; however, the exact underlying mechanism remains unknown [14-17]. The TGF- $\beta /$ Smad signaling pathway is a major pathway involved in fibrogenesis $[7,8]$; therefore, we have investigated whether curcumin exerts any effects on this pathway.

Many cytokines are involved in the development of fibrosis. TGF- $\beta$ and platelet-derived growth factor (PDGF) are the two major cytokines involved in fibrogenesis. PDGF is a potent proliferative cytokine, and TGF- $\beta$ is a potent fibrogenic factor that greatly influences the cellular processes such as differentiation, proliferation, apoptosis, and migration [7,18-20]. After alcohol consumption, the primary metabolite of ethanol and acetaldehyde induces hepatocyte destruction and the release ofprofibrogenic cytokines.Profibrogenic cytokinesstimulate HSC activation through paracrine signaling. After HSC activation, these cells produce TGF- $\beta$ and continued fibrogenesis through paracrine signaling [21,22]. Alcohol could directly activate HSC through the toll-like receptor-4 (TLR4) signaling pathway and thus increase profibrogenic cytokine production [17]

Our study showed that there was a significant increase in proliferation of HSCs and the level of TGF- $\beta$ mRNA expression under direct stimulation with alcohol. This result supports the mechanisms underlying the alcohol toxicity proposed in a previous study, in which the TLR4 signaling pathway led to the production of pro-inflammatory mediators and profibrogenic factor including TGF- $\beta$ and PDGF. In the development of liver fibrosis, TLR4 is also expressed on recruited macrophages, hepatocytes, sinusoidal endothelial cells, and HSC [17]. Consequently, these cells can contribute to liver inflammation through TLR4 signaling, by releasing proinflammatory cytokines and chemokines. As a result, HSCs can also contribute to the development of alcoholic fibrosis by enhancing TGF- $\beta$ signaling [17]. This mechanism explains the results of our study, in which the direct stimulation of HSCs with alcohol can

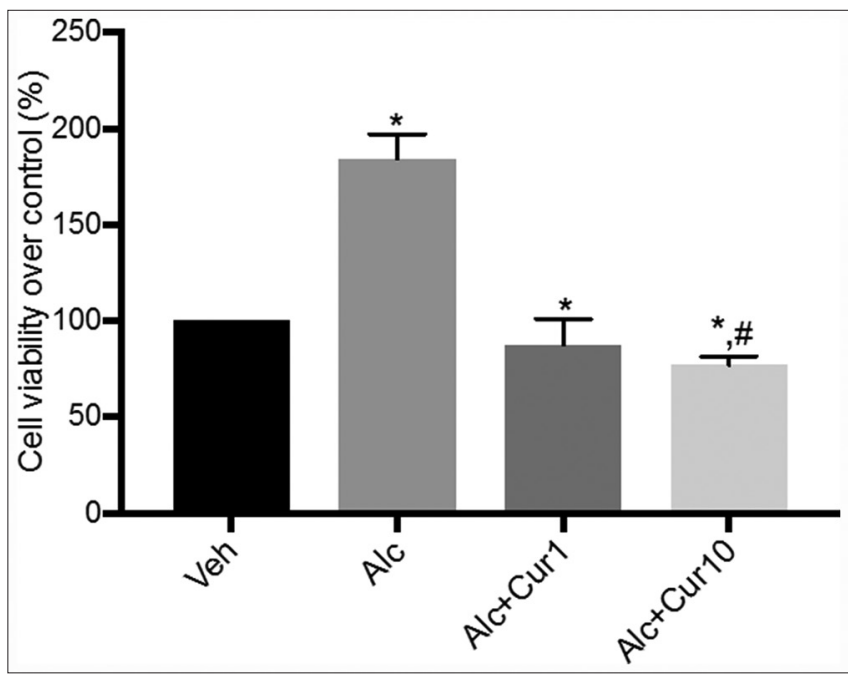

Fig. 1: Number of viable cells after treatment with vehicle only, alcohol, alcohol+curcumin $1 \mu \mathrm{M}$, and alcohol+curcumin $10 \mu \mathrm{M}$.

Results are presented as mean \pm standard deviation, ${ }^{*} \mathbf{p}<0.05$ versus vehicle, $" \mathbf{p}<0.05$ versus alcohol. Veh: Vehicle; Alc: Alcohol; Alc+Cur1: Alcohol+curcumin $1 \mu \mathrm{M}$; Alc+Cur10: Alcohol+curcumin $10 \mu \mathrm{M}$

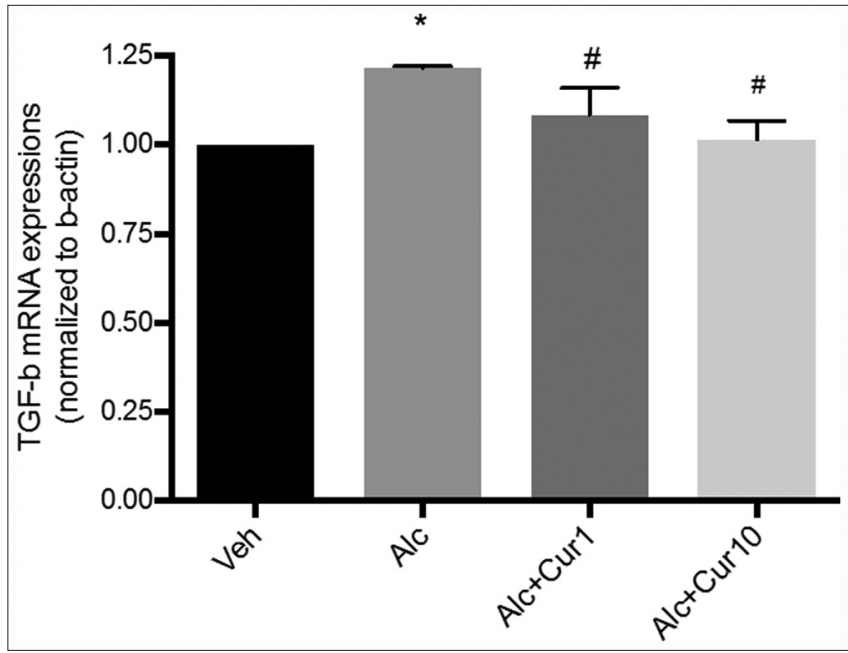

Fig. 2: Transforming growth factor- $\beta$ mRNA expressions after LX-2 treatment with vehicle only, alcohol, alcohol+curcumin $1 \mu \mathrm{M}$, or alcohol+curcumin $10 \mu \mathrm{M}$. Results are presented as mean+standard deviation, ${ }^{*} p<0.05$ versus vehicle, ${ }^{*} p<0.05$ versus alcohol. Veh: Vehicle; Alc: Alcohol; Alc+Cur1: Alcohol+curcumin 1 $\mu \mathrm{M}$; Alc+Cur10: Alcohol+curcumin $10 \mu \mathrm{M}$ 


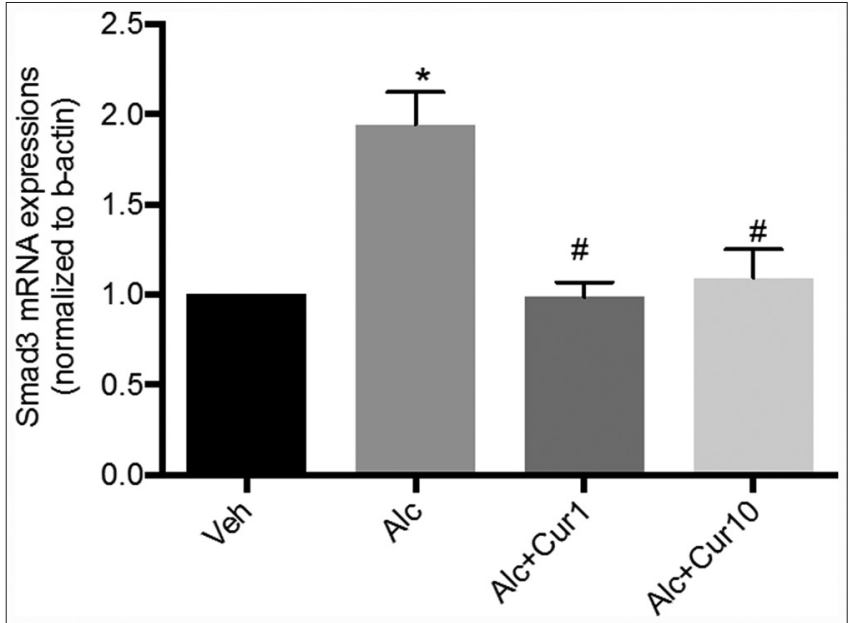

Fig. 3: Smad3 mRNA expressions after LX-2 treatment with vehicle only, alcohol, alcohol+curcumin $1 \mu \mathrm{M}$, or alcohol+curcumin $10 \mu \mathrm{M}$. Results are presented as mean+standard deviation, *: $\mathbf{p}<0.05$ versus vehicle, \#: $\mathbf{p}<0.05$ versus alcohol. Veh: Vehicle; Alc: Alcohol; Alc+Cur1: Alcohol+curcumin $1 \mu \mathrm{M}$; Alc+Cur10: Alcohol+curcumin $10 \mu \mathrm{M}$

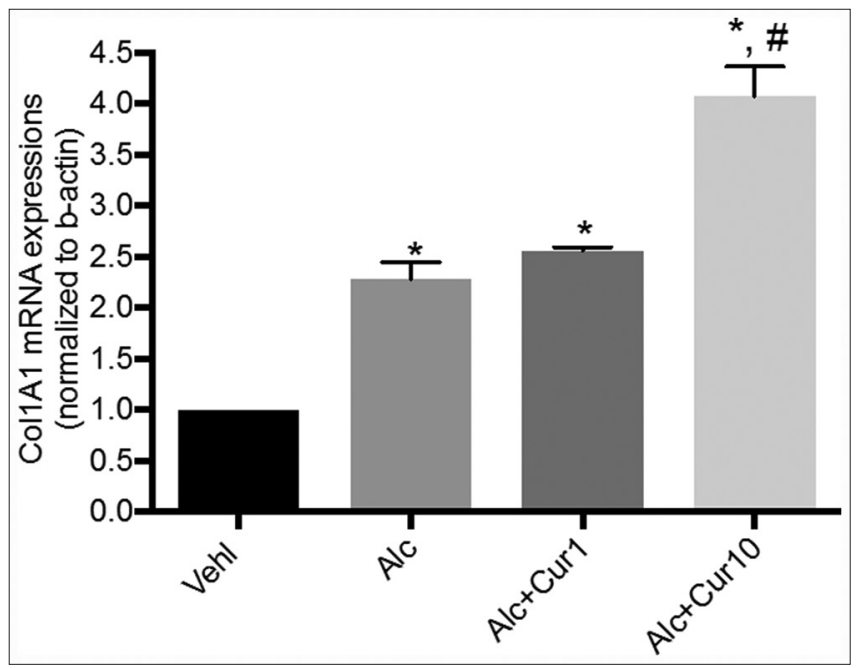

Fig. 4: Collagen $1 \mathrm{A1}$ mRNA expressions after LX-2 treatment with vehicle only, alcohol, alcohol+curcumin $1 \mu \mathrm{M}$, or alcohol+curcumin $10 \mu \mathrm{M}$. Results are presented as mean \pm standard deviation, ${ }^{*} p<0.05$ versus vehicle, ${ }^{\#} p<0.05$ versus alcohol. Veh: Vehicle; Alc: Alcohol; Alc+Cur1: Alcohol+curcumin $1 \mu \mathrm{M}$; Alc+Cur10: Alcohol+curcumin $10 \mu \mathrm{M}$

increase the expression of TGF- $\beta$, thus stimulating HSC proliferation.

The major pathway responsible for HSC activation is TGF- $\beta /$ Smad pathway. There are several types of Smad proteins in the Smad family that is involved in the TGF- $\beta /$ Smad signaling pathway. Yet Smad3, a regulatory Smad protein, seems to be the most important Smad in fibrogenesis. Phosphorylated Smad2/3, in collaboration with coSmad 4, is transported into the nucleus and acts as a transcription factor for the profibrogenic marker $\alpha$-SMA and Col1A1 [7,23,24]. A previous study showed that the activation of HSC was correlated with increasing levels of Smad 3 mRNA expression [17]. In our study, we confirmed that induction by ethanol significantly increased the expression of Smad3 mRNA and profibrogenic marker Col1A1 expression. Activation of HSCs releases TGF- $\beta$ and promotes fibrogenesis by decreasing MMPs and promoting its natural inhibitor, TIMP [7]. In the present study, we confirmed that induction of ethanol significantly increased TIMP-1 expressions. Thus,

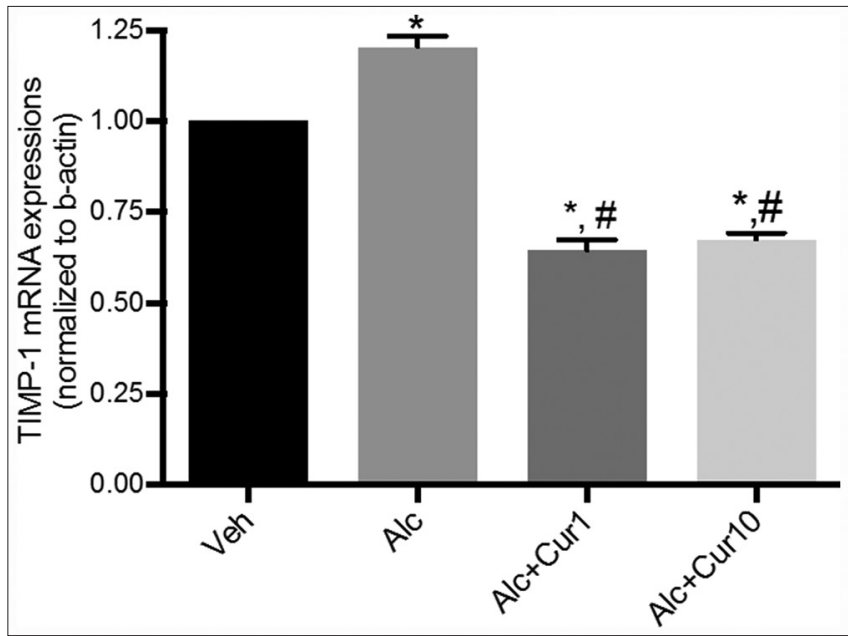

Fig. 5: Tissue inhibitor of metalloproteinases-1 mRNA expressions after LX-2 treatment with vehicle only, alcohol, alcohol+curcumin $1 \mu \mathrm{M}$, or alcohol+curcumin $10 \mu \mathrm{M}$. Results are presented as mean \pm standard deviation, ${ }^{*} \mathbf{p}<0.05$ versus vehicle,

${ }^{\#}$ p $<0.05$ versus alcohol. Veh: Vehicle; Alc: Alcohol; Alc+Cur1: Alcohol+curcumin $1 \mu \mathrm{M}$; Alc+Cur10: Alcohol+curcumin 10 $\mu \mathrm{M}$

we confirmed that, in our model, ethanol induction was successful. Further, HSCs were markedly activated, and all the profibrogenic markers of HSC activation were significantly increased. These results are in accordance with those of a previous study, suggesting that ethanol induction will result in a significant increase in Smad3, TIMP-1, and Col1A1 expression on LX2 cells induced by ethanol $[25,26]$.

Our study showed that curcumin suppressed the proliferation of HSCs under stimulation with ethanol. Curcumin significantly decreased the mRNA TGF- $\beta$ expression, and this effect appeared to be dose dependent. Our result is consistent with a previous study in which curcumin reduced TGF- $\beta$ expressions in the livers of $\mathrm{CCl}_{4}$-treated rats. Altogether, these findings suggest that the downregulation of TGF- $\beta$ by curcumin may be the key underlying mechanisms of its antifibrogenic effects [26]. The examination of the signal molecules in the TGF- $\beta /$ Smad pathway showed that curcumin decreased Smad3 mRNA expression during HSC activation [26]. Our study confirmed that curcumin decreased Smad3 expression. TGF- $\beta$ also promotes fibrogenesis by inhibiting MMPs and promoting its natural inhibitor, TIMPs [27]. Our study showed that inhibition of TGF- $\beta$ in activated HSC by curcumin was in line with decreasing TIMP-1 expressions. This result was in accordance with a previous study done by Liu et al. [26].

As described above, ethanol induction activated the HSCs through TLR signaling. TLR4, one receptor for lipopolysaccharide receptor, can trigger two different signaling pathways, in which one is a myeloid differentiation factor 88-dependent pathway and leads to the rapid activation of nuclear factor- $\kappa \mathrm{B}(\mathrm{NF}-\kappa \mathrm{B})$ [26]. NF- $\mathrm{KB}$ is commonly associated with liver fibrosis, including ALD. Although NF- $\kappa \mathrm{B}$ is not required for the activation of HSCs, an increase in the p65/p50 heterodimer, with a concomitant decrease in the NF- $\mathrm{kB}$ inhibitory protein, IкB $\alpha$, promotes the survival of activated HSCs. Overexpression of NF- $\mathrm{KB}$ in activated HSCs, however, has been shown to inhibit $\alpha 1$ (I) and $\alpha 2(\mathrm{I})$ collagen mRNA expression in culture-activated HSCs $[26,28]$. Many studies showed that curcumin reduces the transcription activation of NF-kB [29-31]. These facts suggest our result that curcumin treatment did not affect Col1A1 expression.

\section{CONCLUSION}

Collectively, our results suggest that the antiproliferative effects of curcumin played by its ability to inhibit TGF- $\beta$ in alcohol-induced HSC. Inhibition of the TGF- $\beta /$ Smad pathway by curcumin decreases Smad3 
and TIMP-1 expressions. Thus, curcumin will affect matrix degradation during fibrogenesis. Therefore, this study suggested the possibility of using curcumin as a potential candidate in the treatment of ALD.

\section{ACKNOWLEDGMENT}

This study was supported by Universitas Indonesia International Publication Grant.

\section{AUTHORS' CONTRIBUTIONS}

RR and BW contributed to the literature search, experimental procedures, and writing of the manuscript. ML and VS contributed to the study design, statistical design, and writing of the manuscript.

\section{CONFLICTS OF INTEREST STATEMENT}

The authors state that there were no conflicts of interest to declare regarding the publication of this work.

\section{REFERENCES}

1. Ghosh Dastidar S, Warner JB, Warner DR, McClain CJ, Kirpich IA. Rodent models of alcoholic liver disease: Role of binge ethanol administration. Biomolecules 2018;8:E3.

2. Singal AK, Kamath PS, Gores GJ, Shah VH. Alcoholic hepatitis: Current challenges and future directions. Clin Gastroenterol Hepatol 2014; 12:555-64.

3. Gaitantzi H, Meyer C, Rakoczy P, Thomas M, Wahl K, Wandrer F, et al. Ethanol sensitizes hepatocytes for TGF- $\beta$-triggered apoptosis. Cell Death Dis 2018;9:51.

4. Liu H, Dong F, Li G, Niu M, Zhang C, Han Y, et al. Liuweiwuling tablets attenuate BDL-induced hepatic fibrosis via modulation of TGF- $\beta / \mathrm{Smad}$ and NF- $\kappa B$ signaling pathways. J Ethnopharmacol 2018;210:232-41.

5. Del Campo JA, Gallego P, Grande L. Role of inflammatory response in liver diseases: Therapeutic strategies. World J Hepatol 2018;10:1-7.

6. Wang Y, Shen RW, Han B, Li Z, Xiong L, Zhang FY, et al. Notch signaling mediated by TGF- $\beta /$ Smad pathway in concanavalin A-induced liver fibrosis in rats. World J Gastroenterol 2017·23 2330-6.

7. Fabregat I, Moreno-Càceres J, Sánchez A, Dooley S, Dewidar B, Giannelli G, et al. TGF- $\beta$ signalling and liver disease. FEBS J 2016; 283:2219-32.

8. Walton KL, Johnson KE, Harrison CA. Targeting TGF- $\beta$ mediated SMAD signaling for the prevention of fibrosis. Front Pharmacol 2017; $8: 461$.

9. Leivonen SK, Lazaridis K, Decock J, Chantry A, Edwards DR, Kähäri VM, et al. TGF- $\beta$-elicited induction of tissue inhibitor of metalloproteinases (TIMP)-3 expression in fibroblasts involves complex interplay between smad3, p38 $\alpha$, and ERK1/2. PLoS One 2013; 8:e57474.

10. Zhu Y, Gu J, Zhu T, Jin C, Hu X, Wang X, et al. Crosstalk between $\operatorname{smad} 2 / 3$ and specific isoforms of ERK in TGF- $\beta 1$-induced TIMP-3 expression in rat chondrocytes. J Cell Mol Med 2017;21:1781-90.

11. Lin PS, Chang HH, Yeh CY, Chang MC, Chan CP, Kuo HY, et al. Transforming growth factor beta 1 increases collagen content, and stimulates procollagen I and tissue inhibitor of metalloproteinase-1 production of dental pulp cells: Role of MEK/ERK and activin receptorlike kinase-5/smad signaling. J Formos Med Assoc 2017;116:351-8.

12. Hu RW, Carey EJ, Lindor KD, Tabibian JH. Curcumin in hepatobiliary disease: Pharmacotherapeutic properties and emerging potential clinical applications. Ann Hepatol 2017;16:835-41.
13. Lin J, Tang Y, Kang Q, Feng Y, Chen A. Curcumin inhibits gene expression of receptor for advanced glycation end-products (RAGE) in hepatic stellate cells in vitro by elevating PPAR $\gamma$ activity and attenuating oxidative stress. Br J Pharmacol 2012;166:2212-27.

14. Bruck R, Ashkenazi M, Weiss S, Goldiner I, Shapiro H, Aeed H, et al. Prevention of liver cirrhosis in rats by curcumin. Liver Int 2007; 27:373-83

15. Kabirifar R, Ghoreshi Z, Rezaifar A, Binesh F, Bamdad K, Moradi A. Curcumin, quercetin and atorvastatin protected against the hepatic fibrosis by activating AMP-activated protein kinase. J Funct Foods 2018;40:341-8.

16. Guo C, Ma J, Zhong Q, Zhao M, Hu T, Chen T, et al. Curcumin improves alcoholic fatty liver by inhibiting fatty acid biosynthesis. Toxicol Appl Pharmacol 2017;328:1-9.

17. Ghorbani Z, Hajizadeh M, Hekmatdoost A. Dietary supplementation in patients with alcoholic liver disease: A review on current evidence. Hepatobiliary Pancreat Dis Int 2016;15:348-60.

18. Xu F, Liu C, Zhou D, Zhang L. TGF- $\beta$ /SMAD pathway and its regulation in hepatic fibrosis. J Histochem Cytochem 2016;64:157-67.

19. Reeves HL, Friedman SL. Activation of hepatic stellate cells-a key issue in liver fibrosis. Front Biosci 2002;7:d808-26.

20. Dooley S, Delvoux B, Lahme B, Mangasser-Stephan K, Gressner AM. Modulation of transforming growth factor beta response and signaling during transdifferentiation of rat hepatic stellate cells to myofibroblasts. Hepatology 2000;31:1094-106

21. Dooley S, ten Dijke P. TGF- $\beta$ in progression of liver disease. Cell Tissue Res 2012;347:245-56.

22. Zheng J, Ma LT, Ren QY, Li L, Zhang Y, Shi HJ, et al. The influence of astragalus polysaccharide and $\beta$-elemene on LX-2 cell growth, apoptosis and activation. BMC Gastroenterol 2014;14:224.

23. Odile S, Fatiha DA, Dominique LG. Up-to-date insight about membrane remodeling as a mechanism of action for ethanol-induced liver toxicity. In: Shimizu I, editor. Trends in Alcoholic Liver Disease ResearchClinical and Scientific Aspects. Croatia: InTech; 2012. p. 159-78.

24. Gressner AM, Weiskirchen R. Modern pathogenetic concepts of liver fibrosis suggest stellate cells and TGF-beta as major players and therapeutic targets. J Cell Mol Med 2006;10:76-99.

25. Chen L, Charrier AL, Leask A, French SW, Brigstock DR. Ethanolstimulated differentiated functions of human or mouse hepatic stellate cells are mediated by connective tissue growth factor. J Hepatol 2011; 55:399-406

26. Liu M, Xu Y, Han X, Yin L, Xu L, Qi Y, et al. Dioscin alleviates alcoholic liver fibrosis by attenuating hepatic stellate cell activation via the TLR4/MyD88/NF- $\kappa$ B signaling pathway. Sci Rep 2015;5:18038.

27. Yao QY, Xu BL, Wang JY, Liu HC, Zhang SC, Tu CT, et al. Inhibition by curcumin of multiple sites of the transforming growth factor-beta1 signalling pathway ameliorates the progression of liver fibrosis induced by carbon tetrachloride in rats. BMC Complement Altern Med 2012; $12: 156$.

28. Thompson KJ, McKillop IH, Schrum LW. Targeting collagen expression in alcoholic liver disease. World J Gastroenterol 2011;17:2473-81.

29. Hackler L Jr., Ózsvári B, Gyuris M, Sipos P, Fábián G, Molnár E, et al. The curcumin analog C-150, influencing NF- $\mathrm{B}$, UPR and akt/notch pathways has potentanticanceractivity invitro and invivo. PLoSOne2016; 11:e0149832.

30. Chung SS, Vadgama JV. Curcumin and epigallocatechin gallate inhibit the cancer stem cell phenotype via down-regulation of STAT3-NFкB signaling. Anticancer Res 2015;35:39-46.

31. Lubbad A, Oriowo MA, Khan I. Curcumin attenuates inflammation through inhibition of TLR-4 receptor in experimental colitis. Mol Cell Biochem 2009;322:127-35. 